\title{
A case report with sacral appendage: Is it accessory penis or human tail?
}

\author{
Canan Kocaoğlu ${ }^{1}$, Çelebi Kocaoğlu², İbrahim Akkoyun ${ }^{1}$, İlkay Eren Karaniş ${ }^{3}$ \\ ${ }^{1}$ Department of Pediatric Surgery, ${ }^{2}$ Department of Pediatrics, ${ }^{3}$ Department of Pathology, Konya Education and Research \\ Hospital, Konya, Turkey. E-mail:drckocaoglu@hotmail.com \\ Received: 16th December 2016, Revised: 9th January 2017, Accepted: 10th January 2017
}

SUMMARY: Kocaoğlu C, Kocaoğlu Ç, Akkoyun İ, Karaniş İE. A case report with sacral appendage: Is it accessory penis or human tail? Turk J Pediatr 2017; 59: 335-337.

Lumbo-sacro-coccygeal appendages are very rare congenital anomalies. It is difficult to say that they are a evolutionary inheritance (tail) from our ancestors or an anomaly (pseudotail) occuring during embrional development. If it is a true tail, this lesion contains adipose and connective tissue, striated muscle, blood vessel and nerves, and is covered by skin. However, if this lesion is a pseudotail, it may be an anomalous prolongation of the coccygeal vertebra, lipoma, teratoma, condrodystrophy or parasitic fetus.

We present an infant with a sacral appendage resembling a penis, and its clinical and pathologic differential diagnosis and management are discussed based on literature. Sacral appendages, such as asaccessory penis or human tail, are treated through simple surgical excision. However, patients must be carefully evaluated regarding teratoma and spinal cord pathology.

Key words: accessory penis, human tail, infant, sacral appendage.

Lumbo-sacro-coccygeal appendages are very rare congenital anomalies. These anomalies are described as a remmant of a structure found in embryonic life or ancestral forms and can be related with other pathologies of the spine and spinal cord, such as spinal dysraphism, meningomyelocele and tethered spinal cord ${ }^{1}$. In addition, the appendages may also be associated with an anomalously prolonged coccygeal vertebra, lipoma, teratoma, condrodystrophy or parasitic fetus ${ }^{2}$.

In the present report, we present an infant with a sacral appendage resembling a penis, and its clinical and pathologic differential diagnosis and management are discussed based on literature.

\section{Case Report}

Born after an uneventful full-term pregnancy, a 6-month-old male infant with birth weight of $3300 \mathrm{~g}$ was admitted to the department with a "finger-like" appendage existing since birth. Physical examination revealed a penisor tail-like structure on the midline sacral region, which was about $30 \mathrm{~mm}$ long, 10 $\mathrm{mm}$ in diameter and purple in color at distal end (Fig. 1). In addition, a spectrum of slight hypertrichosis was present on lumbar region. Considering his age, neurological findings, including anal sphincter tone and developmental milestones were within the normal limits. On external examination, the infant was seen to have normal male genitalia. No cases of similar anomalies were noted in the family members.

As well as lumbo-sacral spine within normal limits on radiography, no occult spinal dysraphism or meningomyelocele was observed on magnetic resonance imaging (MRI) (Fig. 2). Pelvic and abdominal ultrasonography revealed no sign of the extension of the mass or the abnormal formation.

A midline vertical incision was performed by encircling the base of appendage, and the appendage was simply excised. Histological examination of resected specimen revealed a glans-like structure, including nerve, vessel and muscle tissue. No urethra- or testicle-like structure was present (Fig. 3). The infant was discharged on the 3 rd postoperative day. During the follow-up period of 6 months, the infant 


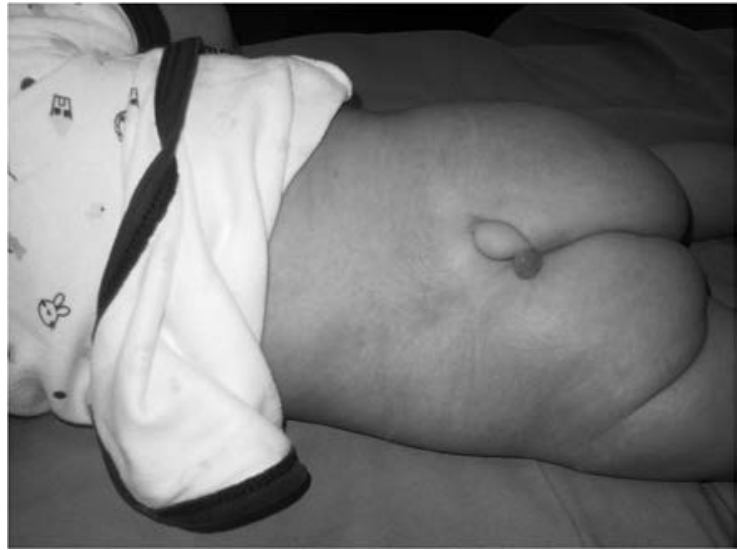

Fig. 1. Photograph showing the sacral appendages

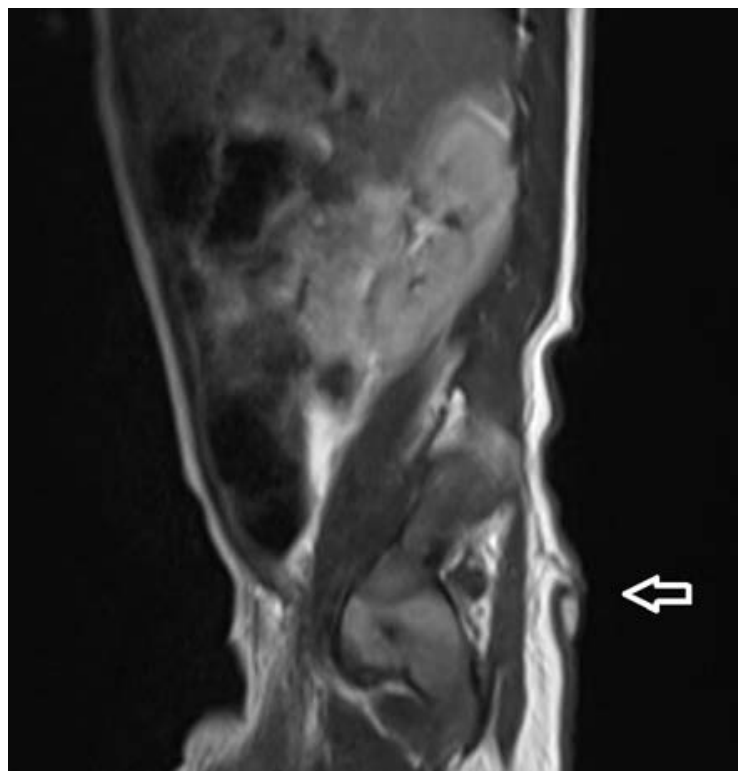

Fig. 2. Preoperative sagittal T1-weighted MR image demonstrating high signal intensity of the tail appendage (white arrow)

displayed normal neurological development and commenced to walk and speak at the 12 th month.

Written informed consent was obtained from the patient's mother for publication of this case report and accompanying images.

\section{Discussion}

The fetal tails usually disappear by the end of the gestational 8th week in human beings. After delivery, the caudal appendage resembling a tail is a quite rare entity ${ }^{1}$. It is difficult to say that the caudal appendage is an evolutionary inheritance (tail) from our ancestors or an anomaly (pseudotail) occurring

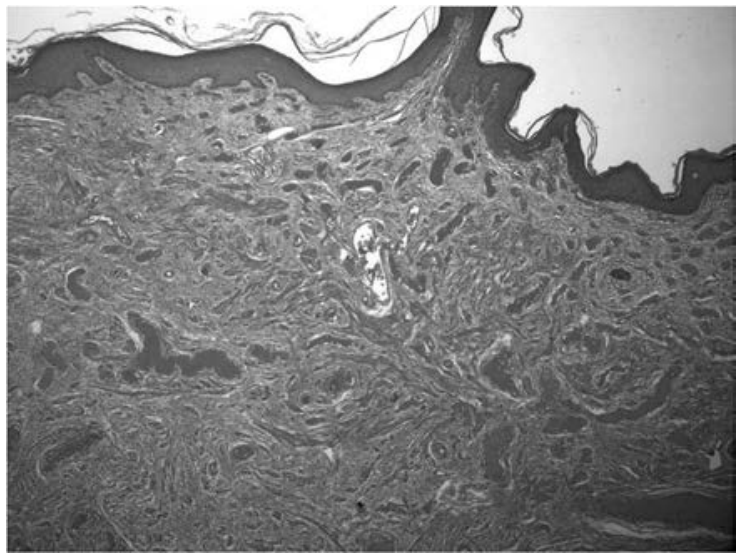

Fig. 3. A polypoid lesion covered by keratinized stratified squamous epithelium and numerous dilated veins, nerves and muscle fibers seenunder the epithelium. HEx100

during embryonal development. If it is a true tail, this lesion contains adipose and connective tissue, striated muscle, blood vessel and nerves, and is covered by skin. However, if this lesion is a pseudotail, it may be an anomalous prolongation of the coccygeal vertebra, lipoma, teratoma, condrodystrophy or parasitic fetus ${ }^{3}$.

Teratomas are most commonly seen in sacrococcygium, mediastinum, central nervous system, retroperitoneum and neck, and may also contain a number of diverse tissues and have abnormal tissue relationships and mixtures ${ }^{4}$. According to the findings of histological examination, the tip of the resected specimen obtained in our case consisted of glans-like structure including nerve, blood vessel and muscles. Despite the presence of the findings mimicking most features of a teratoma, the differentiation into glans-like structure did not precisely fit the characteristics of a teratoma. These histologic findings suggested the presence of a penile structure, rather than a teratoma.

Despite histopathological findings suggesting the accessory penis, the morphogenesis of our case was unclear. It can be speculated, however, that during embriogenesis, multipotential cells may mature along the lines of an accessory penis tissue. On the other hand, the sacral appendages may be an evolutionary inheritance, namely a tail, from our ancestors. The localization of the appendage in sacral region and the lack of its connection with vertebrae or neural tissues supported this hypothesis. So, it was difficult to decide whether the case was an accessory penis or human tail. 
While the number of cases reporting accompanying additional anomalies is limited in literature, the number of cases including sacral appendage but not accompanied by additional anomalies is even rarer. Upon searching the pubmed by entering the terms "human tails and pseudotails", we found only two cases published by Wilkinson and Boylan ${ }^{5}$. The human tail or caudal appendage is usually associated with occult spinal dysraphism ${ }^{1}$. Spina bifida is the most frequent co-existing anomaly in those with both true and pseudotail ${ }^{6}$. Especially in the cases including the components of neural tissue such as meningomyelocele, surgeons should be alert in order to avoid the sequelae, such as neurologic deficits of the lower extremities, bowel and bladder. Thus, the development of irreversible neurologic deficits may be prevented ${ }^{7}$. In our case, no occult or clear spinal dysraphism, or meningomyelocele was detected on MRI. We considered that the level of anomaly was in the sacral region was effective in the absence of neurologic abnormalities.

In the literature, anomalies coexisting with sacral appendages such as congenital dermal sinus, hydrocephalus, corpus callosum abnormalities, heterotopic gray matter, ArnoldChiari malformation and tethered spinal cord were reported ${ }^{8}$. In a report of 200 cases by Tavafoghi et al. ${ }^{9}$, the spinal dysraphism was shown to be a condition associated with cutaneous signs in more than $50 \%$ of instances. In our case, no other accompanying anomalies except for slight hypertrichosis drew attention on lumbar region.

In such cases, the most appropriate timing for the operation is when the infant is at least 3 months old and/or $5 \mathrm{~kg}$ in weight ${ }^{10}$. The most appropriate timing for the resection of a human tail is considered to depend on the histopathological structure of appendages and other accompanying anomalies. The case was admitted to our clinic at the age of six months and operated on immediately. No postoperative complications developed.

The treatment of caudal appendages such as accessory penis or human tail not accompanied by other anomalies is simple surgical excision. However, such patients should be investigated carefully in terms of spinal cord pathologies and other accompanying anomalies before the operation.

\section{REFERENCES}

1. Lin PJ, Chang YT, Tseng HI, Lin JY, Huang YS. Human tail and myelomeningocele. Pediatr Neurosurg 2007; 43: 334-337.

2. Vaishya S, Pandey P. Unusual spinal teratoma with an accessory penis on the back. Childs Nerv Syst 2006; 22: $440-443$.

3. Dao AH, Netsky MG. Human tails and pseudotails. Hum Pathol 1984; 15: 449-453.

4. Ostad M, Mininberg DT, Harbison M, Magid MS Thoracolumbar accessory penis: etiology, diagnosis, and management. Urology 1999; 53: 425-427.

5. Wilkinson CC, Boylan AJ. Proposed caudal appendage classification system; spinal cord tethering associated with sacrococcygeal eversion. Childs Nerv Syst 2016 Aug 6. [Epub ahead of print].

6. Belzberg AJ, Myles ST, Trevenen CL. The human tail and spinal dysraphism. J Pediatr Surg 1991; 26: 12431245.

7. Singh DK, Kumar B, Sinha VD, Bagaria HR. The human tail: rare lesion with occult spinal dysraphism-a case report. J Pediatr Surg 2008; 43: e41-43.

8. Sadashiva N, Beniwal M, Shukla D, Srinivas D. A tale of two "tails:" A curiosity revisited. J Pediatr Neurosci 2016; 11: 153-155.

9. Tavafoghi V, Ghandchi A, Hambrick GW Jr, Udverhelyi GB. Cutaneous signs of spinal dysraphism. Report of a patient with a tail-like lipoma and review of 200 cases in the literature. Arch Dermatol 1978; 114: 573-577.

10. Morioka T, Hashiguchi K, Yoshida F, Nagata S, Miyagi Y, Mihara F, Sasaki T. Dynamic morphological changes in lumbosacral lipoma during the first months of life revealed by constructive interference in steady-state (CISS) MR imaging. Childs Nerv Syst 2007; 23: 415420. 